\title{
Positive association between epiphytes and competitiveness of the brown algal genus Lobophora against corals
}

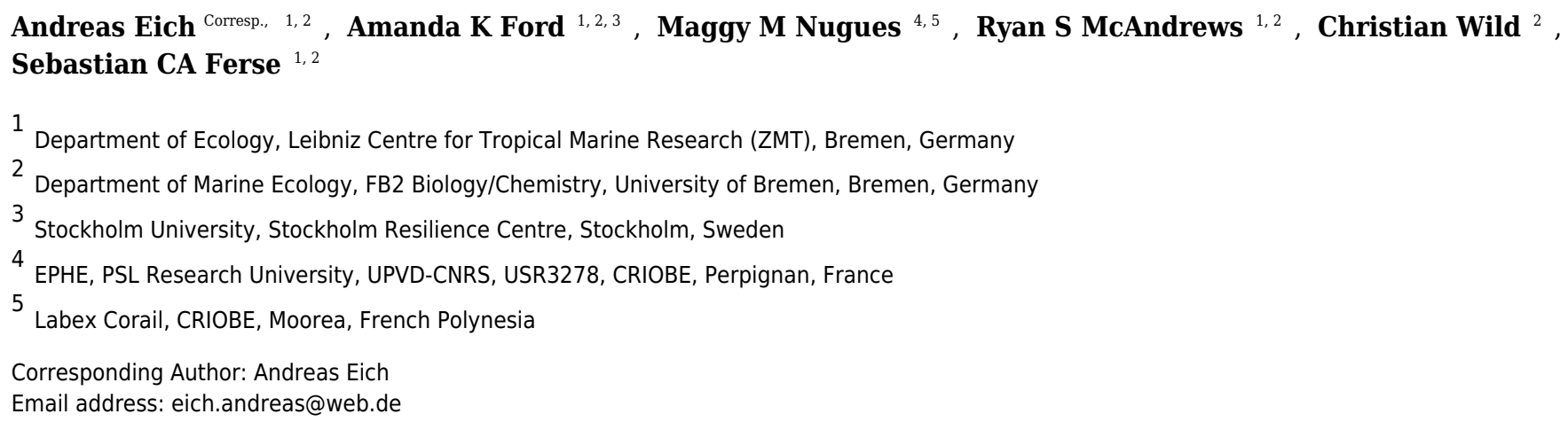

Observations of coral-algal competition can provide valuable information about the state of coral reef ecosystems. Here, we report contact rates and apparent competition states for six shallow lagoonal reefs in Fiji. 81.4\% of examined coral perimeters were found to be in contact with algae, with turf algae (54.7\%) and macroalgae of the genus Lobophora (16.8\%) representing the most frequently observed contacts. Turf algae competitiveness was low, with $21.8 \%$ of coral-turf contacts being won by the algae (i.e. overgrowth or bleaching of coral tissue). In contrast, Lobophora competitiveness against corals was high, with $62.5 \%$ of contacts being won by the alga. The presence of epiphytic algae on Lobophora was associated with significantly greater algal competitiveness against corals, with $75.8 \%$ and $21.1 \%$ of interactions recorded as algal wins in the presence and absence of epiphytes, respectively. Sedimentation rate, herbivorous fish biomass, and coral colony size did not have a significant effect on Lobophora-coral interactions. This research indicates a novel and important role of epiphytes in driving the outcome of coral-algal contacts. 


\section{Positive association between epiphytes and competitiveness of the brown algal}

\section{2 genus Lobophora against corals}

3 Authors:

4 Eich, Andreas ${ }^{\mathrm{a}, \mathrm{b}}$; Ford, Amanda K. ${ }^{\mathrm{a}, \mathrm{b}, \mathrm{c}}$; Nugues, Maggy M. ${ }^{\text {d, e; }}$, McAndrews, Ryan S. ${ }^{\mathrm{a}, \mathrm{b}}$; Wild,

5 Christian $^{\text {b; }}$ Ferse, Sebastian C.A. ${ }^{\text {a, b }}$

7 Affiliations:

8 a: Department of Ecology, Leibniz Centre for Tropical Marine Research (ZMT), Bremen,

9 Germany.

11 b: Department of Marine Ecology, FB2 Biology/Chemistry, University of Bremen, Bremen, 12 Germany.

13

14 c: Stockholm Resilience Centre, Stockholm University, Stockholm 10691, Sweden.

15

d: EPHE, PSL Research University, UPVD-CNRS, USR3278 CRIOBE, Perpignan, France.

17

e: Labex Corail, CRIOBE, Moorea, French Polynesia

19

20 Corresponding author:

21 Andreas Eich, eich.andreas@web.de 


\section{Abstract}

24 Observations of coral-algal competition can provide valuable information about the state of coral

25 reef ecosystems. Here, we report contact rates and apparent competition states for six shallow

26 lagoonal reefs in Fiji. 81.4\% of examined coral perimeters were found to be in contact with

27 algae, with turf algae (54.7\%) and macroalgae of the genus Lobophora (16.8\%) representing the

28 most frequently observed contacts. Turf algae competitiveness was low, with $21.8 \%$ of coral-turf

29 contacts being won by the algae (i.e. overgrowth or bleaching of coral tissue). In contrast,

30 Lobophora competitiveness against corals was high, with $62.5 \%$ of contacts being won by the

31 alga. The presence of epiphytic algae on Lobophora was associated with significantly greater

32 algal competitiveness against corals, with $75.8 \%$ and $21.1 \%$ of interactions recorded as algal

33 wins in the presence and absence of epiphytes, respectively. Sedimentation rate, herbivorous fish

34 biomass, and coral colony size did not have a significant effect on Lobophora-coral interactions.

35 This research indicates a novel and important role of epiphytes in driving the outcome of coral-

36 algal contacts.

\section{Introduction}

39 Coral reefs are rapidly degrading worldwide, with hard corals commonly being replaced by

40 benthic algae (Diaz-Pulido et al. 2009). These changes are triggered by a combination of

41 stressors, including overfishing of herbivores, excess nutrient and organic matter input, global

42 climate change, and emergent marine diseases (Barott et al. 2012). To understand the

43 mechanisms involved in these shifts, it is important to investigate interactions between corals and

44 algae. These interactions typically involve a range of physical, microbial, and chemical

45 mechanisms (McCook et al. 2001; Barott and Rohwer 2012). Algae can damage corals via direct 
46 physical interactions such as shading and abrasion, the exudation of allelopathic substances, and

47 through indirect influences such as the release of dissolved organic carbon (DOC) (Barott and

48 Rohwer 2012). Microorganisms within coral mucus can profit from released DOC and deplete

49 oxygen concentrations in proximity to coral tissue, which can subsequently cause mortality and

50 disease (Barott and Rohwer 2012; Jorissen et al. 2016).

51 Furthermore, the effects of algae on corals depend on the specific coral (Rasher et al. 2011) and

52 algal (Jompa and McCook 2003a; Bonaldo and Hay 2014) species present. Crustose coralline

53 algae generally have positive effects on coral reefs, for example through promoting coral

54 recruitment (Ritson-Williams et al. 2009) and suppressing macroalgal recruitment (Vermeij et al.

55 2011), whereas turf algae can negatively influence coral health through impeding coral

56 recruitment success (Birrell et al. 2005) and reducing tissue thickness (Quan-Young and

57 Espinoza-Avalos 2006). Anthropogenic influence (Barott et al. 2012), particularly sedimentation

58 and terrestrial run-off, can increase the frequency of coral-turf contacts and turf competitiveness

59 (Nugues and Roberts 2003; Gowan et al. 2014).

60 Brown macroalgae within the genus Lobophora have been a focus of recent research because of

61 their rapid increase on many reefs worldwide (e.g. Mumby et al. 2005). This genus can flourish

62 following disturbances such as bleaching events (Diaz-Pulido et al. 2009) and storms (Roff et al.

63 2015), reaching benthic cover of up to 50\% (Slattery and Lesser 2014). Direct contact between

64 Lobophora and corals commonly induces coral bleaching and mortality (Jompa and McCook

65 2002; Slattery and Lesser 2014; Vieira et al. 2016a) and results in decreased coral growth,

66 reproduction, and recruitment (Nugues and Bak 2006). Lobophora can also act as a substrate for

67 a diverse epiphytic community (Fricke et al. 2011). However, few studies to date have 
68 considered the roles of epiphytes in coral-algal interactions or have distinguished the effects of

69 epiphytes from those of their algal hosts.

70 Epiphytes have a wide range of effects on their host, and consequently their influence on host

71 competitiveness is challenging to predict. Epiphytes can stress their host through shading (Round

72 1981), can reduce consumption of host algae by herbivores (D’Antonio 1985; Fong et al. 2006;

73 Smith et al. 2010), and if firmly attached can lead to tissue lesions and/or cause bacterial

74 infections (Fricke et al. 2013). Some epiphytes are hemiparasitic and drain organic carbon from

75 their host using penetrating rhizoids (Garbary and Deckert 2002). If epiphytes act as a stressor to

76 their algal host and reduce algal growth rates, they could potentially decrease the

77 competitiveness of their algal hosts against corals. Alternatively, epiphytes could reinforce

78 competitiveness of their algal hosts by directly damaging corals. For example, a common

79 epiphyte of Lobophora, Anotrichum tenue (Fricke et al. 2011), can overgrow living coral tissue

80 (Jompa and McCook 2003b). Furthermore, by altering the composition and concentration of

81 secondary metabolites in their host (Kremb et al. 2014), epiphytes can deter herbivorous fishes

82 from consuming algal hosts (Karez et al. 2000) and thus increase host competitiveness.

83 The goal of this observational study was to assess the types and outcomes of coral-algal

84 interactions on coral reefs in Fiji and to gain first insights into the relationship between the

85 presence of epiphytes and algal host competitiveness against corals. In addition to characterising

86 the coral-algal interactions and recording the genera involved, we measured herbivorous fish

87 biomass and sedimentation rates as explanatory variables. We expected a negative relationship

88 between herbivorous fish biomass and the number of coral-algal interactions, and also

89 anticipated that higher sedimentations rates would enhance the prevalence of turf algae involved

90 in interactions by deterring herbivory (Bellwood and Fulton 2008). 


\section{Material and methods}

95 Benthic surveys were conducted at two sets of three shallow lagoonal reef sites (4-6 m depth) with increasing distance from each of two rural villages at Beqa Island $\left(18^{\circ} 25^{\prime} \mathrm{S}, 178^{\circ} 08^{\prime} \mathrm{E}\right)$,

97 Fiji (Fig. 1). At each reef, three $10 \mathrm{~m}$ transects were haphazardly placed on the benthos. For the first ten hard coral colonies underneath each transect, we measured (to the nearest centimetre)

the coral perimeter in contact with specific organisms (e.g. algal types, sponges, other corals) and bare substrate, thus additionally obtaining the total perimeter of the coral colony. For each observed coral-algal contact, we recorded the coral and algal genera, the presence of epiphytic algae, and the apparent outcome of the interaction. In this study, epiphytes were defined as all filamentous algae growing on the surface of macroalgae (Fig. 2) and turf algae as filamentous algae with a canopy height below $2 \mathrm{~cm}$ growing on abiotic substrate. A coral-algal interaction was considered as 'alga-winning' if the coral was bleached below or next to the interaction zone or if there was visible overgrowth of the alga over the coral surface, as 'coral-winning' if the coral was visibly overgrowing the algae, or as 'neutral' if neither was observed (Barott et al.

108 2012).

109 At each site, three sediment traps, designed according to Storlazzi et al. (2011), were deployed 110 three times, each for $c a$. three weeks. Sediment material was filtered, dried for $24 \mathrm{~h}$ at $105^{\circ} \mathrm{C}$, 111 and weighed. The abundance of herbivorous fishes (according to categorisations by Green and 112 Bellwood 2009) was assessed for six 30 x $5 \mathrm{~m}$ belt transects per site. Mobile and large fishes (>

$11310 \mathrm{~cm}$ fork length) were counted in a first pass along the transect tape, and smaller, site-attached 
114 fishes were counted on the return pass. All surveys were performed by one surveyor (RSM) at

115 approximately the same time of day (morning - noon), tide (outgoing), and weather conditions

116 (calm) within one month (30.09.2015 - 29.10.2015). Fishes were categorised into $5 \mathrm{~cm}$ size

117 classes (fork length) and the average fish biomass per site was calculated as described by Froese

118 (2006), using species-specific length-weight conversion factors (Green and Bellwood 2009).

119 For each coral colony, the proportion of the colony perimeter in contact with each type of contact

120 category (i.e. algal genera, other benthic organisms, or bare substrate) was calculated (hereon

121 referred to as 'contact rate'). The two most frequently observed algal groups (i.e. turf and

122 Lobophora) were analysed in more detail. For both types of algae, the relationship between

123 contact rate and site was analysed with a generalised linear model. For contacts with turf algae, a

124 generalised linear mixed model incorporating transect nested in site as a random effect was

125 applied to analyse the relationships between contact rate and sedimentation rate, herbivorous fish

126 biomass, coral genus, and colony size (perimeter). For contacts with Lobophora, we also tested

127 the effect of the presence of epiphytes. Furthermore, models were run separately for each of the

128 three most frequently observed coral genera. Following the same approach, the influence of the

129 above parameters on the competitiveness of turf algae and Lobophora was tested for each coral

130 genus incorporating a random factor for the coral colony ID. Competitiveness was defined as the

131 proportion of the coral perimeter in contact with turf algae or Lobophora for which the

132 interaction was classified as 'alga-winning'. Since response values consisted of proportions, a

133 beta distribution was chosen for all models (Kieschnick and McCullough 2003). Proportional

134 data contained the extremes $(0$ and 1$)$ and was therefore transformed by $(y \cdot(n-1)+0.5) / n$,

135 where $n$ is the sample size (Smithson and Verkuilen 2006). Comparisons of groups (i.e. tests

136 comparing between different sites and presence or absence of epiphytes) were only conducted if 
137 at least two groups with at least three replicates each were present after sub-setting the dataframe

138 for the separate analyses of coral genera. All models were reduced by removing the least

139 significant term if a likelihood ratio test between the reduced and unreduced model revealed no

140 significant difference. The effects of explanatory variables were tested using Wald tests. To

141 account for multiple comparisons, $\mathrm{p}$ values within individual analyses (i.e., of contact rate and

142 competitiveness, respectively, both for turf algae and Lobophora) were adjusted after Holm

143 (Holm 1979). All statistical analyses were carried out using R (Version 3.4.2).

144

145 Results

146 On average, $81.4 \pm 2.7 \%$ (mean $\pm \mathrm{SE}, \mathrm{n}=179$ colonies $)$ of coral perimeters and 156 of the 179

147 colonies examined were in contact with algae. Turf algae was the most common algal group (124

148 affected colonies) involved in coral-algal interactions, followed by the macroalga Lobophora (73

149 affected colonies), recorded as being in contact with $54.7 \pm 3.2 \%$ and $16.8 \pm 2.3 \%$ of coral

150 perimeters, respectively (Fig. 3). All interactions involving turf algae or Lobophora were

151 classified either as 'alga-winning' or 'neutral' (i.e. no 'coral-winning' interactions were

152 observed).

153 Contact rates with turf algae increased significantly with sedimentation, while herbivorous fish

154 biomass, coral genus, colony size, and site had no significant effect (Table 1A). Separate

155 analyses for the three most frequent coral genera in contact with turf algae (Porites $n=67$ of 179

156 contacts, Pavona $n=16$, and Acropora $n=12$ ) revealed no significant effect for any of the

157 explanatory variables and species (Table 1A). None of the explanatory variables were found to

158 have a significant effect on turf algal competitiveness when considering all coral types $(21.8 \pm$

$1593.4 \%$ 'alga-winning' contacts, Fig. 3A), or when analyses were run separately for the three most 
160 common coral genera (Table 1A). The effect of site could not be analysed for Acropora corals,

161 since after sub-setting the data, only one site remained with at least three replicates. The contact

162 rates of Lobophora were significantly higher when epiphytes were present (Table 1B).

163 Sedimentation rate, herbivorous fish biomass, coral genus, site, and colony size did not influence

164 Lobophora contact rate. When analysing contact rates of the three most frequent coral genera

165 individually (Porites $n=44$, Acropora $n=8$, and equally frequent Favites and Pavona $n=6$ ), no

166 significant effects were found (Table 1B). Most interactions (62.5 $\pm 5.2 \%)$ between Lobophora

167 and corals were classified as 'alga-winning' (Fig 3C), and in total $12.4 \pm 2.1 \%$ of the perimeter

168 of all corals was negatively affected by Lobophora (i.e. 'alga-winning', Fig. 3C). Site,

169 sedimentation rate, herbivorous fish biomass, coral genus and colony size (perimeter) did not

170 significantly influence Lobophora competitiveness. However, the presence of epiphytes had a

171 highly significant (positive) effect on the proportion of 'alga-winning' Lobophora-coral

172 interactions (Fig. 3C, Table 1B). Consistent with the results of the overall model, the presence of

173 epiphytes increased 'alga-winning' rates for Porites-Lobophora contacts. No significant effects

174 of the explanatory variables were found for the other coral genera (Table 1B). For Acropora and

175 Pavona, the effects of epiphytes and site could not be analysed due to insufficient replication

176 after sub-setting of the data. Likewise, the effect of site could not be tested for Pavona corals.

177

\section{Discussion}

179 This study investigated the contact rates and apparent outcomes of interactions between corals

180 and algae in a lagoonal reef system in Fiji. Contrary to our expectations, herbivorous fish

181 biomass had no influence on coral-algal interactions. However, as expected, we found a positive

182 correlation between the rates of sedimentation and of coral-turf algae contact. This observation 
183 was also made previously in Saint-Lucia, Caribbean (Nugues and Roberts 2003), and in Moorea,

184 French Polynesia (Gowan et al. 2014), and could be explained by deterred grazing, which was

185 not measured directly and does not necessarily have to be reflected in herbivorous fish biomass.

186 This influence was not observed when coral genera were analysed separately, probably because

187 replication was reduced due to sub-setting of the data.

188 We found a negative influence of Lobophora on the coral perimeter, which was approximately

189 twice as high as previously reported for Lobophora variegata in the Caribbean island of Curaçao

$190(12.4 \pm 2.1 \%$ vs. maximally $5.7 \%$ of negatively influenced coral perimeter, Nugues and Bak

191 2006). Epiphytes significantly increased the proportion of interactions in which Lobophora were

192 reported to be winning. We assume that this overall effect on the investigated corals was mainly

193 caused by the high proportion of Porites-Lobophora contacts, which were strongly affected by

194 the presence of epiphytes. Other coral genera (Acropora, Favites and Pavona) were far less

195 common, which resulted in low replication and high variance when running the model separately

196 for these genera. The number of Pavona corals observed was so low that solely interactions with

197 Lobophora overgrown by epiphytes were found (i.e. no interactions were recorded between

198 Pavona and Lobophora without epiphytes present), precluding statistical analysis of this factor.

199 Generally, results for these less common genera should be interpreted with caution.

200 The enhanced competitiveness when epiphytes were present on Lobophora could be driven by

201 direct impacts of the epiphytes themselves on neighbouring corals and/or via indirect effects on

202 the algal host. In New Caledonia, bleaching of coral perimeters in contact with Lobophora

203 herderacea has been proposed to be caused by associated epiphytic filamentous algae (Vieira et

204 al. 2015). Functionally, epiphytes are similar to turf algae, which can damage corals (McCook et

205 al. 2001; Quan-Young and Espinoza-Avalos 2006). In this study however, turf algae were 
206 associated with a relatively higher proportion of neutral interactions, suggesting that epiphytic

207 filamentous algae and filamentous turf algae growing on abiotic substrate differ in their

208 competitiveness, potentially due to differences in their species composition.

209 Indirect effects of epiphytic algae on coral-algal interactions could occur via chemical alterations

210 of the algal host. For example, extracts of Lobophora overgrown by epiphytes have a higher

211 activity against human immunodeficiency virus than extracts from Lobophora without epiphytes

212 (Kremb et al. 2014). As Lobophora can damage corals via different allelochemicals (Rasher and

213 Hay 2010; Rasher et al. 2011; Slattery and Lesser 2014; Vieira et al. 2016b), increased

214 production or concentration of any of these chemicals in the presence of epiphytes could

215 significantly influence host competitiveness in coral-algal interactions. Another potential

216 explanation for the elevated competitive potential of Lobophora with epiphytes is that epiphytes

217 deter grazing on algal hosts (D’Antonio 1985; Fong et al. 2006; Smith et al. 2010). Competition

218 with corals can induce increased algal production of allelopathic chemicals at the expense of the

219 production of anti-herbivore substances, which can result in higher algal palatability (Rasher and

220 Hay 2014). If epiphytes release Lobophora from grazing pressure, they could further facilitate

221 production of allelochemicals that enhance algal competitiveness without the usual associated

222 trade-off of increased palatability. Other parameters such as the duration of the coral-Lobophora

223 contact or the species composition of the epiphytal community may also have had an influence

224 on the outcome of the competitions. Due to infrastructure limitations stemming from a different

225 initial scope of the study and the difficulty of accurately identifying filamentous algal species in

226 the field, it was not possible to determine the species of epiphytes and turf algae involved in the

227 interactions or perform an analysis of algal extracts for potential allelochemical compounds. This 
228 constitutes an important avenue for future studies of the role of epiphytes in affecting coral-algal

229 interactions and the underlying mechanisms.

230

231

232 Conclusions

233 These results provide strong indications that the competitiveness of Lobophora against corals,

234 particularly those within the genus Porites, is enhanced when epiphytes are growing on

235 Lobophora. This study suggests a need to consider associated epiphytic algal communities when

236 investigating coral-algal interactions. Although this study was limited in its scope and was

237 unable to characterise the epiphytic assemblage or the chemical compounds involved in the

238 Lobophora-coral contacts, we hope that future studies will extend on our findings to better

239 understand the dynamics of coral-algal interactions. Further research could additionally

240 experimentally manipulate epiphytes to determine whether this observation is a result of direct

241 negative effects of epiphytic algae on corals or of an increased competitiveness of Lobophora

242 and should investigate potential differences in algal communities growing on dead corals versus

243 on macroalgae.

244

\section{Acknowledgements}

246 We would like to thank the village elders of Dakuibeqa for research permission, and Manassa

247 and Bose for their help during fieldwork. Furthermore, we want to thank the ZMT dive team for

248 their support. Comments by two anonymous reviewers helped to improve the manuscript. The

249 research reported in this paper contributes to the Programme on Ecosystem Change and Society

250 (www.pecs-science.org). 


\section{References}

Barott KL, Rohwer FL (2012) Unseen players shape benthic competition on coral reefs. Trends Microbiol 20:621-628

Barott KL, Williams GJ, Vermeij MJA, Harris J, Smith JE, Rohwer FL, Sandin SA (2012) Natural history of coral-algae competition across a gradient of human activity in the Line Islands. Mar Ecol Prog Ser 460:1-12

Bellwood DR, Fulton CJ (2008) Sediment-mediated suppression of herbivory on coral reefs: Decreasing resilience to rising sea-levels and climate change? Limnol Oceanogr 53:26952701

Birrell CL, McCook LJ, Willis BL (2005) Effects of algal turfs and sediment on coral settlement. Mar Pollut Bull 51:408-14

Bonaldo RM, Hay ME (2014) Seaweed-coral interactions: Variance in seaweed allelopathy, coral susceptibility, and potential effects on coral resilience. PLoS One 9:30-34

D'Antonio C (1985) Epiphytes on the rocky intertidal red alga Rhodomela larix (Turner) C. Agardh: Negative effects on the host and food for herbivores? J Exp Mar Bio Ecol 86:197218

Diaz-Pulido G, McCook LJ, Dove S, Berkelmans R, Roff G, Kline DI, Weeks S, Evans RD, Williamson DH, Hoegh-Guldberg O (2009) Doom and Boom on a Resilient Reef: Climate Change, Algal Overgrowth and Coral Recovery. PLoS One 4:e5239

Fong P, Smith TB, Wartian MJ (2006) Epiphytic cyanobacteria maintain shifts to macroalgal dominance on coral reefs following ENSO disturbance. Ecology 87:1162-1168

Fricke A, Titlyanova TV, Nugues MM, Bischof K (2011) Depth-related variation in epiphytic communities growing on the brown alga Lobophora variegata in a Caribbean coral reef. Coral Reefs 30:967-973

Fricke A, Titlyanova TV, Nugues MM, Bischof K (2013) Neosiphonia howei (Ceramiales: Rhodomelaceae) - a common epiphyte of the spreading coral reef alga Lobophora variegata (Dictyotales: Dictyotaceae). Mar Biodivers Rec 6:1-6

Froese R (2006) Cube law, condition factor and weight-length relationships: History, metaanalysis and recommendations. J Appl Ichthyol 22:241-253

Garbary DJ, Deckert RJ (2002) Three Part Harmony - Ascophyllum and Its Symbionts. In: Seckbach J. (eds) Symbiosis: Mechanisms and Model Systems. Springer Netherlands, Dordrecht, pp 309-321

Gowan JC, Tootell JS, Carpenter RC (2014) The effects of water flow and sedimentation on interactions between massive Porites and algal turf. Coral Reefs 33:651-663

Green AL, Bellwood DR (2009) Monitoring functional groups of herbivorous reef fishes as indicators of coral reef resilience - A practical guide for coral reef managers in the Asia Pacific region. IUCN Work Gr Clim Chang Coral Reefs

Holm S (1979) A Simple Sequentially Rejective Multiple Test Procedure A Simple Sequentially Rejective Multiple Test Procedure. Scand J Stat 6:65-70

Jompa J, McCook LJ (2002) The effects of nutrients and herbivory on competition between a hard coral (Porites cylindrica) and a brown alga (Lobophora variegata). Limnol Oceanogr 
294

295

296

297

298

299

300

301

302

303

304

305

306

307

308

309

310

311

312

313

314

315

316

317

318

319

320

321

322

323

324

325

326

327

328

329

330

331

332

333

334

335

336

337

338

339

47:527-534

Jompa J, McCook LJ (2003a) Coral-algal competition: macroalgae with different properties have different effects on corals. Mar Ecol Prog Ser 258:87-95

Jompa J, McCook LJ (2003b) Contrasting effects of turf algae on corals: massive Porites spp. are unaffected by mixed-species turfs, but killed by the red alga Anotrichium tenue. Mar Ecol Prog Ser 258:79-86

Jorissen H, Skinner C, Osinga R, de Beer D, Nugues MM (2016) Evidence for water-mediated mechanisms in coral-algal interactions. Proc R Soc London B Biol Sci 283:

Karez R, Engelbert S, Sommer U (2000) "Co-consumption" and "protective coating": Two new proposed effects of epiphytes on their macroalgal hosts in mesograzer-epiphyte-host interactions. Mar Ecol Prog Ser 205:85-93

Kieschnick R, McCullough BD (2003) Regression analysis of variates observed on $(0,1)$ : percentages, proportions and fractions. Stat Model An Int J 3:193-213

Kremb S, Helfer M, Kraus B, Wolff H, Wild C, Schneider M, Voolstra CR, Brack-Werner R (2014) Aqueous extracts of the marine brown alga Lobophora variegata inhibit HIV-1 infection at the level of virus entry into cells. PLoS One 9:e103895

McCook LJ, Jompa J, Diaz-Pulido G (2001) Competition between corals and algae on coral reefs: A review of evidence and mechanisms. Coral Reefs 19:400-417

Mumby PJ, Foster NL, Fahy EAG (2005) Patch dynamics of coral reef macroalgae under chronic and acute disturbance. Coral Reefs 24:681-692

Nugues MM, Bak RPM (2006) Differential competitive abilities between Caribbean coral species and a brown alga: a year of experiments and a long-term perspective. Mar Ecol Prog Ser 315:75-86

Nugues MM, Roberts CM (2003) Coral mortality and interaction with algae in relation to sedimentation. Coral Reefs 22:507-516

Quan-Young LI, Espinoza-Avalos J (2006) Reduction of zooxanthellae density, chlorophyll a concentration, and tissue thickness of the coral Montastraea faveolata (Scleractinia) when competing with mixed turf algae. Limnol Oceanogr 51:1159-1166

Rasher DB, Hay ME (2010) Chemically rich seaweeds poison corals when not controlled by herbivores. Proc Natl Acad Sci U S A 107:9683-9688

Rasher DB, Hay ME (2014) Competition induces allelopathy but suppresses growth and antiherbivore defence in a chemically rich seaweed Competition induces allelopathy but suppresses growth and anti-herbivore defence in a chemically rich seaweed. Proc R Soc B 20132615 ,

Rasher DB, Stout EP, Engel S, Kubanek J, Hay ME (2011) Macroalgal terpenes function as allelopathic agents against reef corals. Proc Natl Acad Sci 108:17726-17731

Ritson-Williams R, Arnold SN, Fogarty ND, Steneck RS, Vermeij MJA, Paul VJ (2009) New perspectives on ecological mechanisms affecting coral recruitment on reefs. Smithson Contrib Mar Sci 437-457

Roff G, Doropoulos C, Zupan M, Rogers A, Steneck RS, Golbuu Y, Mumby PJ (2015) Phase shift facilitation following cyclone disturbance on coral reefs. Oecologia 178:1193-1203

Round FE (Frank E (1981) The ecology of algae. Cambridge University Press,

Slattery M, Lesser MP (2014) Allelopathy in the tropical alga Lobophora variegata (Phaeophyceae): Mechanistic basis for a phase shift on mesophotic coral reefs? J Phycol 50:493-505

Smith TB, Fong P, Kennison R, Smith J (2010) Spatial refuges and associational defenses

PeerJ reviewing PDF | (2018:06:28735:2:0:CHECK 21 Dec 2018) 
340

341

342

343

344

345

346

347

348

349

350

351

352

353

354

355

356

357

358 promote harmful blooms of the alga Caulerpa sertularioides onto coral reefs. Oecologia 164:1039-1048

Smithson M, Verkuilen J (2006) A better lemon squeezer? Maximum-likelihood regression with beta-distributed dependent variables. Psychol Methods 11:54-71

Storlazzi CD, Field ME, Bothner MH (2011) The use (and misuse) of sediment traps in coral reef environments: Theory, observations, and suggested protocols. Coral Reefs 30:23-38

Vermeij MJA, Dailer ML, Smith CM (2011) Crustose coralline algae can suppress macroalgal growth and recruitment on Hawaiian coral reefs. Mar Ecol Prog Ser 422:1-7

Vieira C, Engelen AH, Guentas L, Aires T, Houlbreque F, Gaubert J, Serrao EA, Clerck O De, Payri CE (2016a) Species specificity of bacteria associated to the brown seaweeds Lobophora (Dictyotales, Phaeophyceae) and their potential for induction of rapid coral bleaching in Acropora muricata. Front Microbiol 7:1-13

Vieira C, Payri C, De Clerck O (2015) Overgrowth and killing of corals by the brown alga Lobophora hederacea (Dictyotales, Phaeophyceae) on healthy reefs in New Caledonia: A new case of the epizoism syndrome. Phycol Res 63:152-153

Vieira C, Thomas OP, Culioli G, Genta-Jouve G, Houlbreque F, Gaubert J, De Clerck O, Payri CE (2016b) Allelopathic interactions between the brown algal genus Lobophora (Dictyotales, Phaeophyceae) and scleractinian corals. Sci Rep 6:18637:1-11 
Figure 1

Beqa island in the south of Fiji (see arrow) with locations of the six study sites (stars) close to the village of Dakuibeqa and Dakuni.

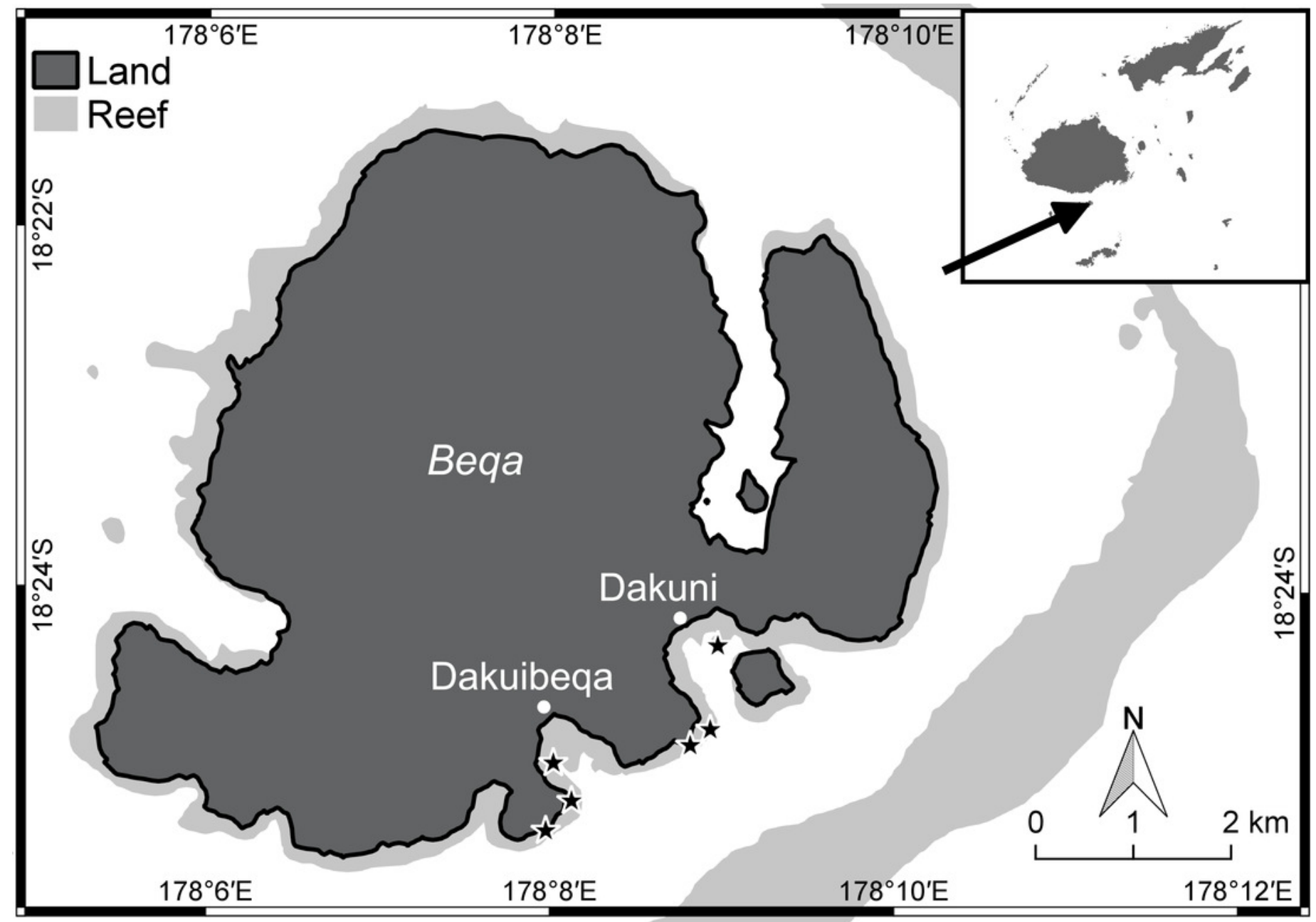


Figure 2

Lobophora covered with filamentous epiphytes.

Scale ticks are in mm. Photo by Andreas Eich.

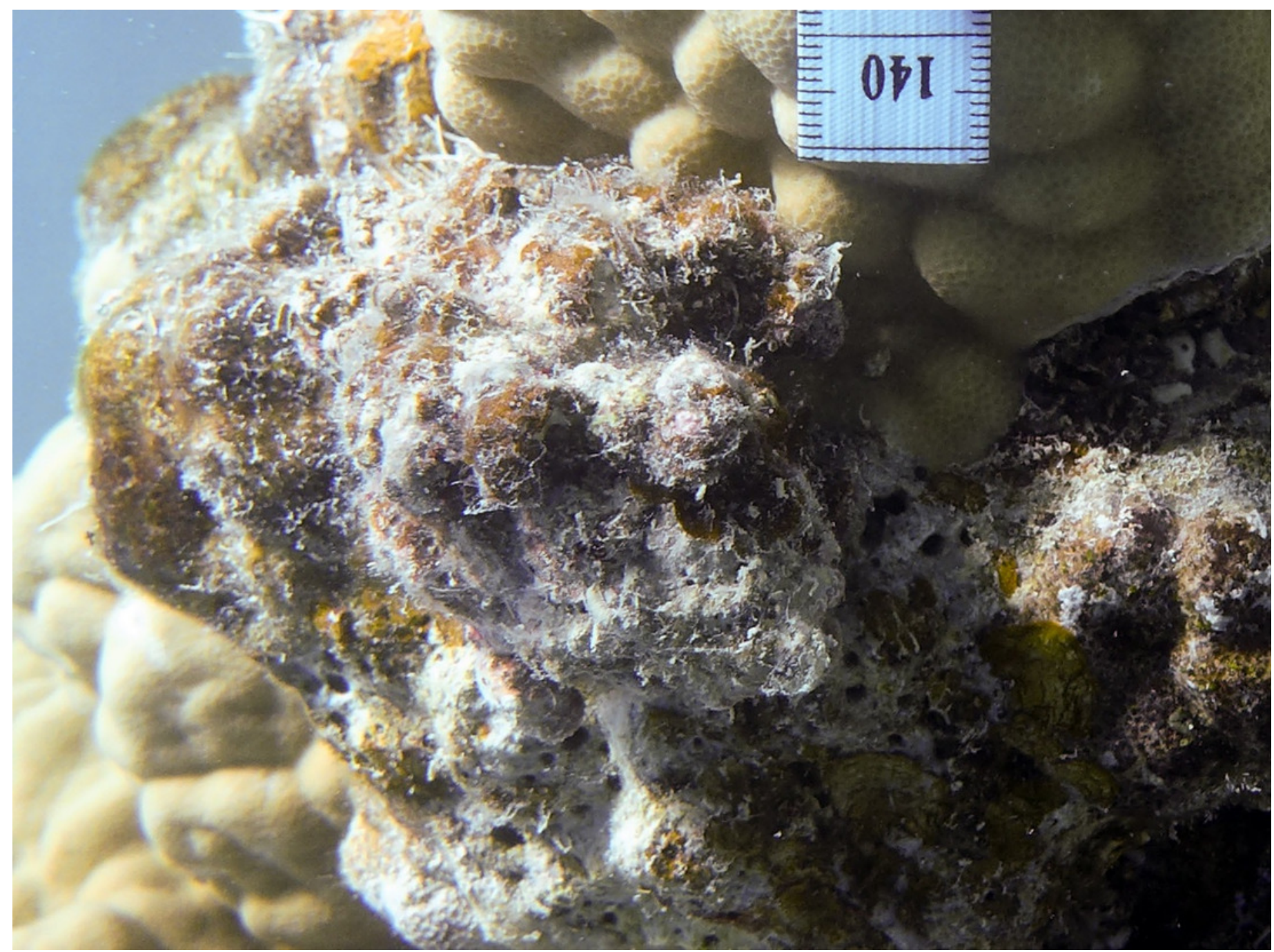




\section{Figure 3}

Overview of observed coral-algae contacts.

A) Mean percentage $( \pm S E)$ of coral perimeter in contact with turf algae for which turf algae apparently won the interaction. B) Proportions of coral perimeter in contact with different algae: Turf algae ('turf', green), Lobophora ('Lobo', brown), other phototrophic organisms like macroalgae (e.g. Padina or Halimeda) or benthic cyanobacteria ('other phototrophic, light grey), benthic invertebrates like sponges or corals ('other benthic', dark grey), and abiotic substrate like sand, rubble, or recently dead coral skeleton ('abiotic', white), C) Mean percentage $( \pm \mathrm{SE}$ ) of coral perimeter in contact with Lobophora with ('yes') and without epiphytes ('no') for which Lobophora apparently won the interaction.

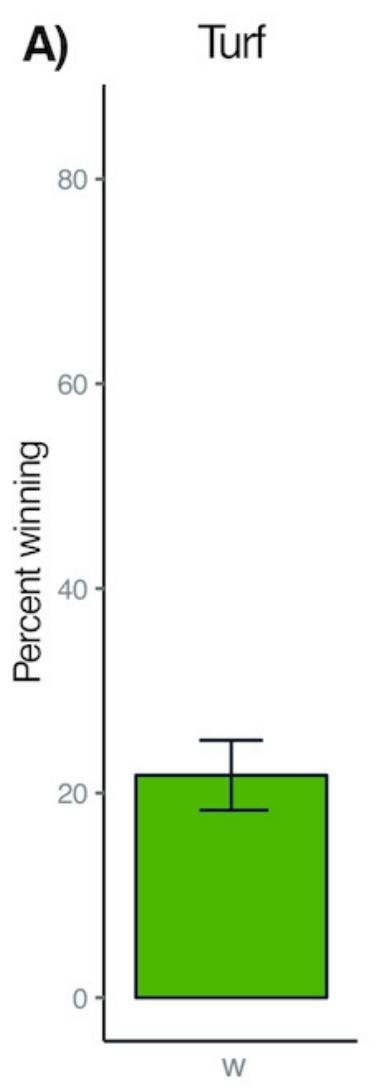

B)
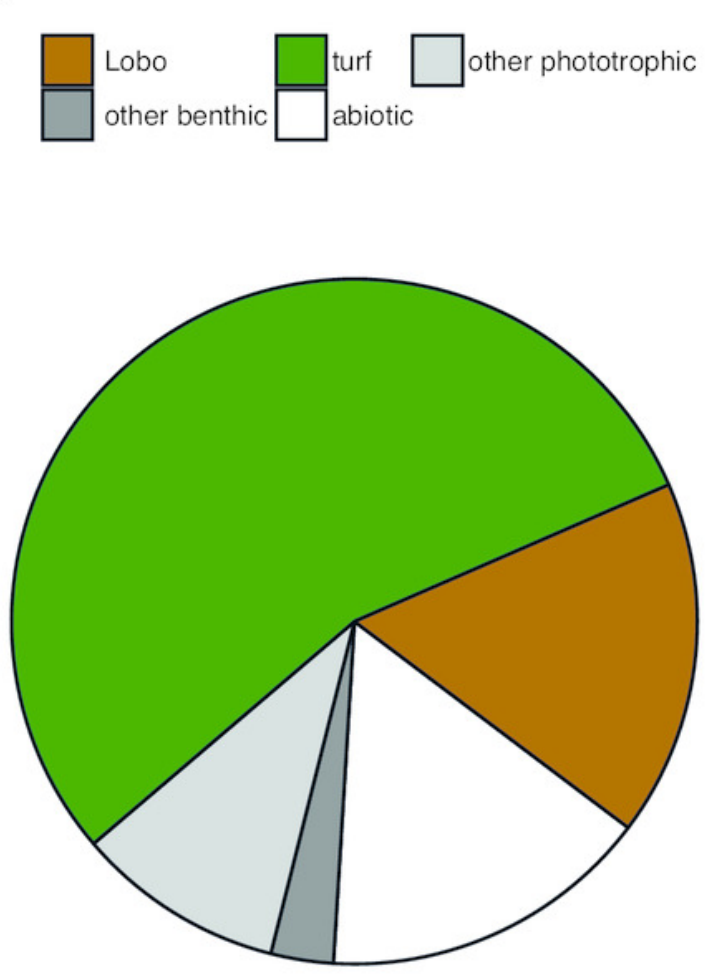

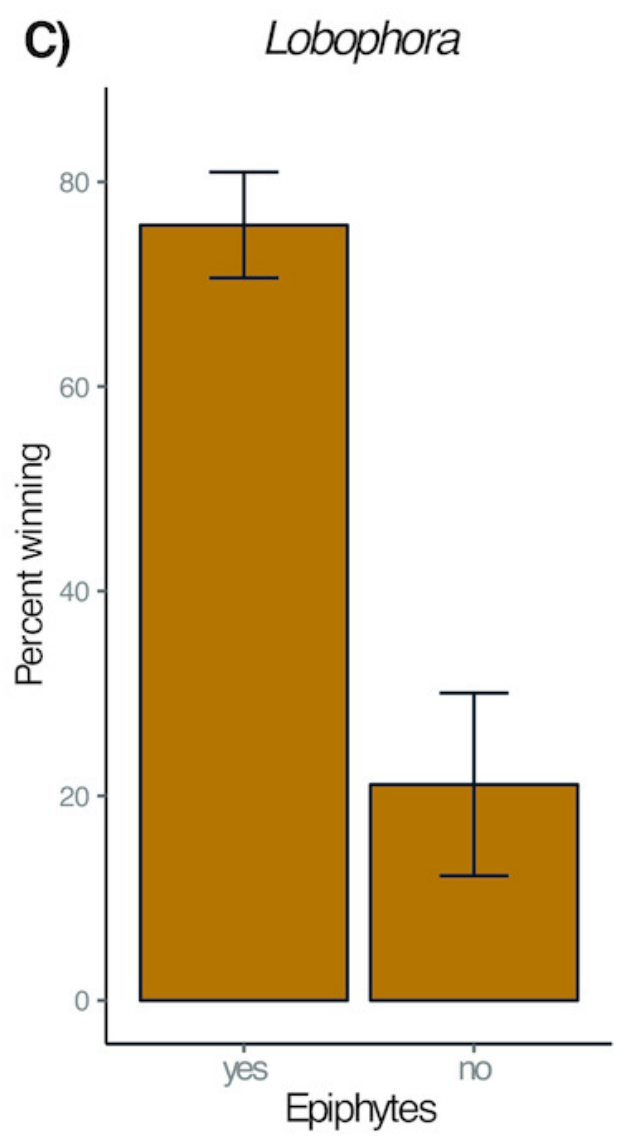




\section{Table $\mathbf{1}$ (on next page)}

Effects of sedimentation (SED), herbivorous fish biomass (HFB), coral perimeter (CP), presence of epiphytes (EPI), site, and genus (GEN) on interactions of coral colonies with turf $(A)$ and Lobophora (B).

Separate analyses were run for total percentage of contact ('contact rates', above) and for percentage of contact for which the interaction was apparently won by the alga ('competitiveness', below). Results are shown for GLM analyses of overall coral contacts with turf and Lobophora, and for GLMM analyses run separately for the 3 and 4 main coral genera in contact with algae, respectively. P-values were adjusted for multiple comparisons after Holm (Holm 1979). 'n.s.' = not significant, 'n.t.' = not tested because number of groups < 2 or number of replicates within groups $<3$. 
A) Turf

Contact rates

main effect

\begin{tabular}{|c|c|c|c|c|c|c|c|}
\hline \multirow{2}{*}{ Overall } & n & SED & HFB & $\mathbf{C P}$ & EPI & SITE & GEN \\
\hline & 124 & $\chi^{2}(d f=1)=9.948, p<0.05$ & n.s. & n.s. & - & n.s. & n.s. \\
\hline \multicolumn{8}{|c|}{ Coral genus } \\
\hline Porites & 67 & n.s. & n.s. & n.s. & - & n.s. & - \\
\hline Pavona & 16 & n.s. & n.s. & n.s. & - & n.s. & - \\
\hline Acropora & 12 & n.s. & n.s. & n.s. & - & n.s. & - \\
\hline \multicolumn{3}{|c|}{ Competitiveness } & & ma & & & \\
\hline & n & SED & HFB & $\mathbf{C P}$ & EPI & SITE & GEN \\
\hline
\end{tabular}

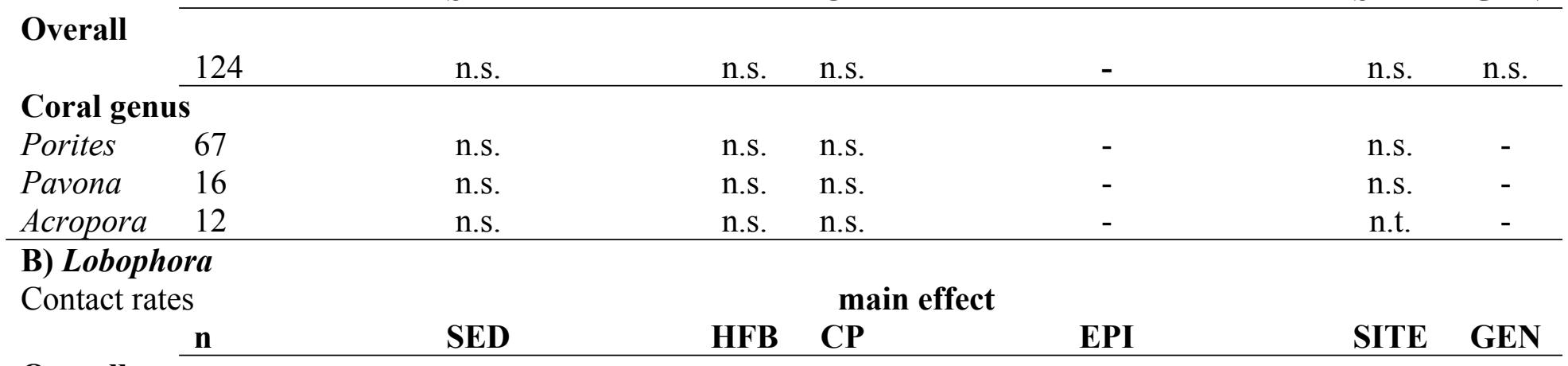

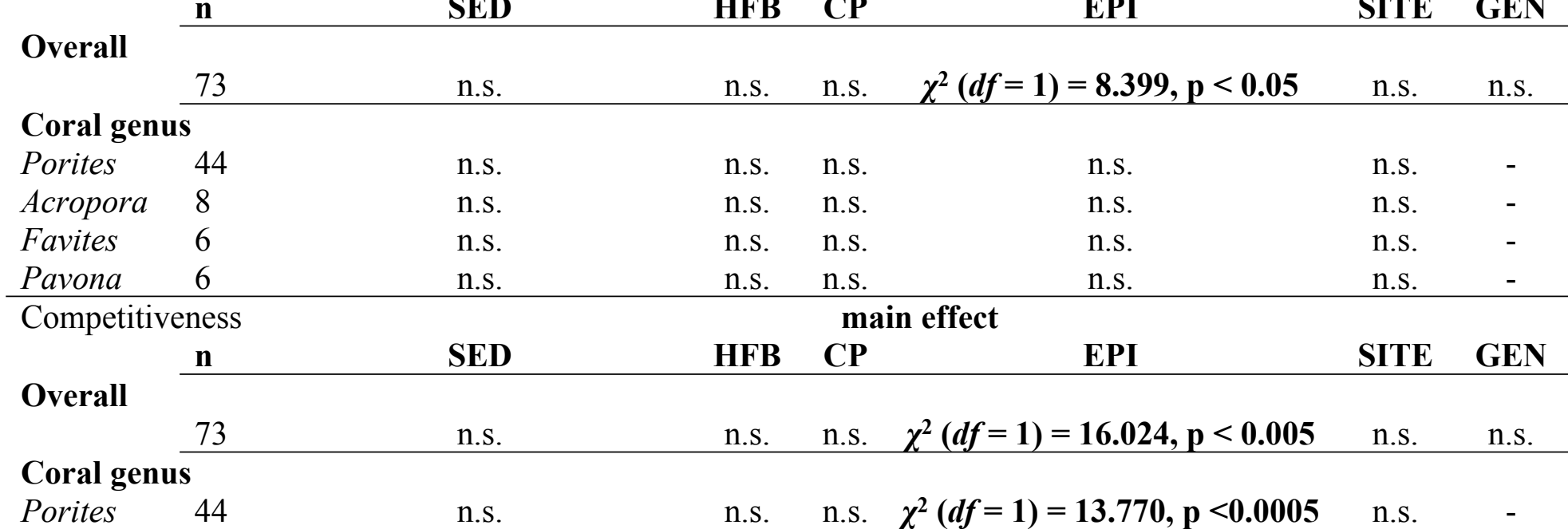




\begin{tabular}{|c|c|c|c|c|c|c|}
\hline Acropora & 8 & n.s. & n.s. & n.s. & n.t. & n.t. \\
\hline Favites & 6 & n.s. & n.s. & n.s. & n.s. & n.t. \\
\hline Pavona & 6 & n.s. & n.s. & n.s. & n.t. & n.t. \\
\hline
\end{tabular}

